\title{
PEMAKAIAN JENIS BH (BREAST HOLDER) MEMPENGARUHI NYERI PUNGGUNG PADA IBU HAMIL DI POLI BKIA RUMAH SAKIT ISLAM SURABAYA
}

\author{
Elanda Pebianita Garini*, R. Khairiyatul Afiyah** \\ (UNUSA, FKK, Prodi S1 Keperawatan, Jl. SMEA No 57 Surabaya) \\ dark_zaoldyeck@ymail.com
}

\begin{abstract}
ABSTRACK : Back pain in pregnant women can disturb her daily activities, therfore she needs much more lying. Wearing a proper $B H$ will help reducing a strain on the back. The purpose of this study is to determine the relationship using of the type of BH (Breast Holder) with back pain in pregnant women in Children and Maternity Department of Islamic Hospital Surabaya. Study design is analytic with cross sectional approach. Population were all pregnant women in trimester II and III by 52 person, the samples were 46 respondents taken by simple random sampling technique. Independent variables is using the types of BH (Breast Holder), the dependent variable is back pain. It's instruments are observation and interviews, data then analyzed by Chi-Square test with significance level $\alpha=0.05$ when $\rho<\alpha$ so Ho is rejected it means there is a connection using the type of BH (Breast Holder) with back pain. The most part (67.4\%) of respondents uses the reguler $B H$ and the most part (65.2\%) of respondents do have back pain. Chi-square test results obtained $\rho=0.000<\alpha=(0.05)$ Ho rejected, means there is a relationship the use of the type BH (Breast Holder) with back pain. Wearing BH (Breast Holder) gives influence in back pain. Maternity bra can reduce back pain during pregnancy. Hopefully the nurse spreads the educational information about the importance of wearing maternity bra to pregnant women.
\end{abstract}

\begin{abstract}
ABSTRAK : Nyeri punggung pada ibu hamil dapat mengakibatkan gangguan aktivitas sehari-hari sehingga ibu lebih banyak berbaring. Pemakaian jenis $\mathrm{BH}$ yang tepat dapat mengurangi regangan pada punggung. Penelitian ini bertujuan mengetahui hubungan pemakaian jenis BH (Breast Holder) dengan nyeri punggung pada ibu hamil di Poli BKIA Rumah Sakit Islam Surabaya. Desain penelitian analitik dengan pendekatan cross sectional. Populasinya ibu hamil trimester ke-II dan ke-III sebesar 52 orang, sampel 46 responden diambil dengan teknik simple random sampling. Variabel independen pemakaian jenis BH (Breast Holder), variabel dependen nyeri punggung. Instrumen penelitian menggunakan observasi dan wawancara data dianalisis menggunakan uji Chi-Square dengan tingkat kemaknaan $\alpha=0,05$ apabila $\rho<\alpha$ maka $\mathrm{H}_{\mathrm{o}}$ ditolak artinya ada hubungan pemakaian jenis BH (Breast Holder) dengan nyeri punggung. Sebagian besar $(67,4 \%)$ responden menggunakan $\mathrm{BH}$ biasa, dan sebagian besar responden $(65,2 \%)$ mengalami nyeri punggung. Hasil uji chi-square diperoleh $\rho=$ $0,000<\alpha=(0,05) \mathrm{H}_{\mathrm{o}}$ ditolak artinya ada hubungan pemakaian jenis $\mathrm{BH}$ (Breast Holder) dengan nyeri punggung. Penggunaan $\mathrm{BH}$ (Breast Holder) mempengaruhi nyeri punggung. Maternity bra dapat mengurangi nyeri punggung pada saat hamil. Diharapkan perawat meningkatkan pemberian pendidikan kesehatan tentang pentingnya penggunaan maternity bra kepada ibu hamil.
\end{abstract}

Kata Kunci : jenis BH (Breast Holder), nyeri punggung kehamilan 


\section{PENDAHULUAN}

Kehamilan adalah suatu proses fisiologis, terkadang dapat menimbulkan akibat yang bersifat patologis. Perubahan tersebut dimulai dari nidasi terjadi, yaitu ibu merasakan mual, muntah, pusing bahkan kadang-kadang gejala ini berlebihan sehingga mengharuskan ibu untuk rawat inap. Pada kehamilan lanjut, muncul keluhankeluhan salah satunya adalah nyeri punggung. Nyeri punggung adalah ketidaknyamanan yang terjadi di bawah costa dan di atas bagian inferior gluteal (Burton, 2004).

Seiring dengan bertambahnya usia kehamilan, punggung ibu hamil berubah bahu tertarik ke belakang sebagai akibat pembesaran abdomen yang menonjol dan untuk mempertahankan keseimbangan tubuh karena kelengkungan tulang belakang ke arah dalam secara berlebihan yang biasa disebut lordosis. Semakin bertambah usia kandungan janin menjadi semakin besar sehingga lengkungan punggung bawah semakin bertambah. Hal ini juga dapat memperberat nyeri punggung (Wahyuni dan Prabowo E, 2012).

Dari hasil wawancara tentang nyeri punggung dan jenis BH (Breast Holder) yang dipakai pada ibu hamil yang dilakukan peneliti pada tanggal 2 Januari 2014 di Poli BKIA Rumah Sakit Islam Surabaya didapatkan dari sepuluh ibu hamil, tujuh ibu hamil trimester III mengalami nyeri punggung, jenis $\mathrm{BH}$ yang digunakan $\mathrm{BH}$ yang tidak berpenopang dan bertali kecil. Dua ibu hamil trimester II merasakan nyeri punggung, satu ibu hamil mengatakan memakai jenis $\mathrm{BH}$ biasa tanpa penopang dan satu ibu hamil mengatakan memakai jenis BH yang berpenopang dengan tali dan pengait yang lebar sejak kehamilan pertama, ibu tersebut mengatakan mengalami nyeri punggung pada saat merasa kelelahan karena banyak beraktifitas. Ada satu ibu hamil trimester II mengatakan tidak mengalami nyeri punggung dan selalu menggunakan $\mathrm{BH}$ yang berpenopang namun tidak berkawat dengan pengait dan tali $\mathrm{BH}$ lebar.

Nyeri punggung pada wanita hamil disebabkan oleh faktor mekanika yang mempengaruhi kelengkungan tulang belakang oleh perubahan sikap statis dan penambahan beban pada saat ibu hamil (Wahyuni dan Prabowo, 2012). Peningkatan kadar progesteron juga dapat menimbulkan relaksasi ligamen yang menopang sendi. Seiring dengan pertambahan usia kehamilan, relaksasi sendi sakroiliaka dan simfisis pubis turut menciptakan instabilitas pelvis dalam kadar tertentu sehingga menghasilkan ketegangan tambahan pada otot punggung dan paha.

Perut ibu hamil yang membesar mengubah pusat gravitasi menjadi ke arah depan, sehingga lebih menarik lengkungan punggung bawah (Utami, Shinta, 2008). Semua hal ini menyebabkan beban untuk punggung dari derajat ringan hingga berat. Karena berat uterus pada kehamilan aterm dan isinya dapat mencapai $6 \mathrm{~kg}$, wanita hamil sering kali menyandarkan punggungnya untuk mempertahankan keseimbangan tubuh (equilibrium). Kemiringan batang tubuh ke belakang ini merupakan karakteristik kehamilan dan menyebabkan ketegangan pada otot dan ligamen punggung dan paha kondisi ini menyebabkan rasa sakit dan nyeri yang cukup banyak dan sering dirasakan di akhir kehamilan.

Nyeri punggung pada kehamilan dapat diatasi dengan pemilihan jenis $\mathrm{BH}$ 
yang tepat. Jenis $\mathrm{BH}$ yang tepat untuk ibu hamil adalah yang mempunyai penopang atau kubah, pengait dan tali $\mathrm{BH}$ yang lebar sehingga membuat ibu hamil merasa nyaman. Dengan

\begin{tabular}{llll}
\hline No & Jenis BH & $\begin{array}{l}\text { Frekuen } \\
\text { si }\end{array}$ & $\begin{array}{l}\text { Persenta } \\
\text { se (\%) }\end{array}$ \\
\hline 1 & $\begin{array}{l}\text { Maternity } \\
\text { bra }\end{array}$ & 15 & 32,6 \\
2 & BH biasa & 31 & 67,4 \\
\hline & Jumlah & 46 & 100 \\
\hline
\end{tabular}

pemakaian jenis $\mathrm{BH}$ yang tepat, kubah atau penopang dapat menyangga posisi payudara agar terangkat normal karena payudara ibu akan membesar selama proses kehamilan, pengait dan tali yang lebar berfungsi membantu bahu untuk menopang berat janin yang semakin besar seiring bertambahnya usia kehamilan, pemakaian jenis $\mathrm{BH}$ yang

\begin{tabular}{clcc}
\hline No & $\begin{array}{c}\text { Nyeri } \\
\text { punggun } \\
\text { g }\end{array}$ & $\begin{array}{c}\text { Frekuen } \\
\text { si }\end{array}$ & $\begin{array}{c}\text { Persentase } \\
(\%)\end{array}$ \\
\hline 1 & $\begin{array}{l}\text { Tidak } \\
\text { nyeri } \\
\text { punggun } \\
\text { g } \\
2\end{array}$ & 16 & 34,8 \\
& $\begin{array}{l}\text { Nyeri } \\
\text { punggun } \\
\text { g }\end{array}$ & 30 & 65,2 \\
\hline & Jumlah & 46 & 100 \\
\hline
\end{tabular}

tepat juga dapat dapat mengurangi regangan pada punggung. Sokongan yang tepat untuk payudara ini bersifat kondusif untuk postur yang baik dan membantu mengurangi sakit punggung (Reeder dkk, 2013 \& Neil, 2008).

\section{METODE}

Jenis penelitian ini adalah analitik dengan pendekatan cross sectional. Populasi pada penelitian adalah ibu hamil trimester II dan III di Poli BKIA Rumah Sakit Islam Surabaya pada bulan Maret 2014 sebesar 52 orang. Sampel dalam penelitian ini sebagian ibu hamil trimester II dan III di Poli BKIA Rumah Sakit Islam Surabaya sebesar 46 orang. Pengambilan sampel pada penelitian ini menggunakan teknik probability sampling secara Simple Random Sampling. Instrumen yang digunakan adalah observasi dan wawancara.

\section{Hasil}

Hasil data khusus berisi karakteristik responden menurut jenis $\mathrm{BH}$ (Breast Holder) yang digunakan, kejadian nyeri punggung dan hubungan pemakaian jenis BH (Breast Holder) dengan nyeri punggung pada ibu hamil.

a. Karakteristik responden menurut jenis BH yang digunakan

Tabel 5.7 Distribusi responden berdasarkan pemakaian jenis $\mathrm{BH}$ di Poli BKIA Rumah Sakit Islam Surabaya. Sumber : Data primer, Maret 2014

Berdasarkan tabel 5.7 bahwa sebagian besar responden $(67,4 \%)$ menggunakan jenis BH biasa.

b. Karakteristik responden menurut nyeri punggung

Tabel 5.8 Distribusi responden berdasarkan nyeri punggung di Poli BKIA Rumah Sakit Islam Surabaya.

Sumber : Data primer, Maret 2014

Berdasarkan tabel 5.8 bahwa sebagian besar responden $(65,2 \%)$ mengalami nyeri punggung.

c. Hubungan pemakaian jenis $\mathrm{BH}$ dengan nyeri punggung pada ibu hamil.

Tabel 5.9 Tabulasi silang hubungan pemakaian jenis $\mathrm{BH}$ dengan nyeri punggung pada ibu hamil di poli BKIA Rumah Sakit Islam Surabaya . 


\begin{tabular}{|c|c|c|c|c|}
\hline \multirow[b]{2}{*}{ No } & \multicolumn{4}{|c|}{ Nyeri punggung } \\
\hline & $\begin{array}{c}\text { Jenis } \\
\text { BH }\end{array}$ & $\begin{array}{c}\text { Tidak } \\
\text { nyeri } \\
\text { punggu } \\
\text { ngn( } \% \\
\text { ) }\end{array}$ & $\begin{array}{c}\text { Nyeri } \\
\text { punggu } \\
\text { ng } \\
\text { n(\%) }\end{array}$ & $\begin{array}{c}\text { Juml } \\
\text { ah } \\
\text { n(\%) }\end{array}$ \\
\hline 1 & $\begin{array}{l}\text { Materni } \\
\text { ty bra }\end{array}$ & $\begin{array}{c}13(86,8 \\
)\end{array}$ & $2(13,3)$ & $\begin{array}{c}15(10 \\
0)\end{array}$ \\
\hline 2 & $\begin{array}{l}\mathrm{BH} \\
\text { biasa }\end{array}$ & $3(9,7)$ & $\begin{array}{c}28(90,3 \\
)\end{array}$ & $\begin{array}{c}31(10 \\
0)\end{array}$ \\
\hline & Jumlah & $16(100)$ & $30(100)$ & $\begin{array}{c}46(10 \\
0)\end{array}$ \\
\hline
\end{tabular}

Sumber : Data primer, Maret 2014

Berdasarkan tabel 5.9 berdasarkan tabel di atas dari 15 responden yang menggunakan maternity bra hampir seluruhnya $13(86,8 \%)$ responden tidak mengalami nyeri punggung. Dari 31 responden yang menggunakan jenis $\mathrm{BH}$ biasa hampir seluruhnya $28 \quad(90,3 \%)$ responden mengalami nyeri punggung.

Berdasarkan uji chi-square program SPSS 16 for windows didapatkan tingkat signifikan $\mathrm{p}=0,000<0,05$ yang berarti $\mathrm{H}_{0}$ artinya ada hubungan pemakaian jenis $\mathrm{BH}$ dengan nyeri punggung pada ibu hamil di Poli BKIA Rumah Sakit Islam Surabaya.

\section{PEMBAHASAN}

Menurut Linden, Ellyana (2012) nyeri punggung pada kehamilan adalah nyeri yang dirasakan pada ibu hamil yang disebabkan oleh pertumbuhan janin dalam kandungan yang kemudian mengakibatkan terjadi perubahan pusat gravitasi, sehingga terjadi penyesuaian postur tubuh yang menyebabkan ketidaknyamanan pada ibu hamil dan dapat terjadi pada trimester I, trimester II dan trimester III dimasa kehamilan.
Hormon yang dihasilkan saat hamil juga dapat mempengaruhi punggung. Beberapa hormon kehamilan menyebabkan ligamen yang berada diantara tulang pelvis (panggul) melunak dan sendi melonggar sebagai persiapan untuk melahirkan ( Bull dan Archard, 2007). Nyeri punggung juga dapat bertahan lama sehingga membuat ibu hamil merasa tidak nyaman sampai saat persalinan.

Jenis BH (Breast Holder) yang tepat untuk ibu hamil adalah yang mempunyai penopang atau kubah, pengait dan tali $\mathrm{BH}$ yang lebar sehingga membuat ibu hamil merasa nyaman. Dengan pemakaian jenis $\mathrm{BH}$ yang tepat, kubah atau penopang dapat menyangga posisi payudara agar terangkat normal karena payudara ibu akan membesar selama proses kehamilan, pengait dan tali yang lebar berfungsi membantu bahu untuk menopang berat janin yang semakin besar seiring bertambahnya usia kehamilan, pemakaian jenis $\mathrm{BH}$ yang tepat juga dapat dapat mengurangi regangan pada punggung. Sokongan yang tepat untuk payudara ini bersifat kondusif untuk postur yang baik dan membantu mengurangi sakit punggung (Reeder dkk, 2013 \& Neil, 2008).

Dari hasil penelitian banyak ibu hamil yang mengalami nyeri punggung salah satu faktor yang menyebabkan nyeri punggung adalah pemakaian $\mathrm{BH}$ (Breast Holder) yang kurang tepat selama masa kehamilan. Ini menunjukkan penggunaan $\mathrm{BH}$ (Breast Holder) mempengaruhi nyeri punggung. Nyeri punggung yang berlangsung selama kehamilan dapat mengganggu aktivitas ibu hamil sehari - hari sehingga menyebabkan ibu hamil lebih banyak berbaring. Maternity bra dapat mengurangi nyeri punggung pada saat hamil. Diharapkan perawat 
meningkatkan pemberian pendidikan kesehatan tentang pentingnya penggunaan maternity bra kepada ibu hamil.

\section{SIMPULAN}

Berdasarkan hasil penelitian yang dilakukan di Poli BKIA Rumah Sakit Islam Surabaya tentang pemakaian jenis BH (Breast Holder) dan nyeri punggung pada ibu hamil didapatkan simpulan sebagai berikut :

1. Ibu hamil di Poli BKIA Rumah Sakit Islam Surabaya sebagian besar menggunakan jenis $\mathrm{BH}$ (Breast Holder) biasa.

2. Ibu hamil di Poli BKIA Rumah Sakit Islam Surabaya sebagian besar mengalami nyeri punggung.

3. Pemakaian jenis BH (Breast Holder) berhubungan dengan nyeri punggung pada ibu hamil di Poli BKIA Rumah Sakit Islam Surabaya.

\section{DAFTAR PUSTAKA}

Arikunto (2006). Prosedur Penelitian. Jakarta, Rineka Cipta.

Bull, dan Archard (2007). Nyeri

Punggung, Jakarta, Penerbit

Erlangga

Burton (2004). European Guidelines for Prevention in low Back Pain, http://www.backpaineurope.org.

Artikel diakses tanggal 3 Desember 2013 pukul 12.45 WIB

Francis Cheung, Theresa (2008).

Manajemen Berat Badan

Kehamilan, Jakarta, Arcan

Ferrer, Helen (2001). Perawatan Maternitas, Jakarta, EGC

Judha, Mohammad (2012). Teori Pengukuran Nyeri dan Nyeri Persalinan.Jogjakarta, Muha Medika

Kusmiyati (2009). Perawatan Ibu Hamil. Jogjakarta, Fitrimaya
Linden, Ellyana (2012). Panduan Terapi Aman Selama Kehamilan. Jakarta, PT.ISFI Penerbitan

Mandar, R. (2004). Nyeri Persalinan. Jakarta, EGC

Manuaba, Ida Bagus Gde (2010). Ilmu Kebidanan Penyakit dan Keluarga Berencana untuk Pendidikan Bidan Edisi 2. Jakarta, EGC

Maria, Ulfah.(2009). Ketidakmyamanan Kehamilan

TrimesterIII.www.youngermidwife.b logspot.com. Artikel diakses tanggal 7 Januari 2014 pukul 14.30 WIB

Mubarok, WL, dkk (2007). Promosi Kesehatan, Sebuah Pengantar Proses Belajar Mengajar dalam Pendidikan, Yogyakarta, Graha Ilmu

Neil, W.R. (2008). Panduan Lengkap Perawatan Kehamilan. Jakarta, Dian Rakyat

Nursalam (2011). Konsep dan Penerapan Metodologi Penelitian Ilmu Keperawatan. Jakarta, Salemba Medika

Reeder, Martin, Griffin, K. (2013). Keperawatan Maternitas : Kesehatan Wanita, Bayi \& Keluarga. Edisi 18. Jakarta, Dian Rakyat

Smeltzer, dan Bare, (2002). Buku Ajar Keperawatan Medikal Bedah : Brunner Suddarth, Vol. I . Jakarta, EGC

Syaifuddin (2009). Asuhan Maternal dan Neonatal. Jakarta, YBPSP

Utami, Shinta (2008). Info Penting Kehamilan. Jakarta, Penerbit Dian Rakyat

Wahyuni dan Prabowo, E. (2012). Manfaat Kinesiotaping Untuk Mengurangi Nyeri Punggung Bawah Pada Kehamilan Trimester ke-3. http://publikasiilmiah.ums.ac.id. 
Artikel diakses tanggal 3 Januari 2014 pukul 09.50 WIB

Wasis (2008). Pedoman Riset Praktis

Untuk Profesi Keperawatan.

Jakarta, EGC 